\title{
Impulsivity influences food intake in women with generalized anxiety disorder
}

\author{
Natasha Kim de O. da Fonseca, ${ }^{1}$ iD Roberta D. Molle, ${ }^{2,3}$ Marianna de A. Costa, ${ }^{4}$ iD Francine G. \\ Gonçalves, ${ }^{4}$ Alice C. Silva, ${ }^{5}$ Ylana Rodrigues, ${ }^{5}$ Menna Price, ${ }^{6}$ Patrícia P. Silveira, ${ }^{7,8}$ Gisele G. Manfro ${ }^{1,4}$ \\ ${ }^{1}$ Programa de Pós-Graduação em Neurociências, Universidade Federal do Rio Grande do Sul (UFRGS), Porto Alegre, RS, Brazil. ${ }^{2}$ Programa \\ de Pós-Graduação em Saúde da Criança e do Adolescente, UFRGS, Porto Alegre, RS, Brazil. ${ }^{3}$ Faculdade INEDI-CESUCA, Cachoeirinha, \\ RS, Brazil. ${ }^{4}$ Programa de Pós-Graduação em Psiquiatria e Ciências do Comportamento, UFRGS, Porto Alegre, RS, Brazil. ${ }^{5}$ Graduação em \\ Nutrição, UFRGS, Porto Alegre, RS, Brazil. ${ }^{6}$ Department of Psychology, Swansea University, Swansea, Wales, UK. ${ }^{7}$ Department of Psychiatry \\ and Sackler Program for Epigenetics \& Psychobiology, McGill University, Montreal, Quebec, Canada. ${ }^{8}$ Ludmer Centre for Neuroinformatics \\ and Mental Health, Douglas Mental Health University Institute, Montreal, Quebec, Canada.
}

\begin{abstract}
Objective: Eating behavior is affected by psychological and neurocognitive factors. However, little is known about this relationship in anxious patients. Our aim was to investigate the associations between impulsivity, inhibitory control, energy-dense food consumption, and body mass index (BMI) in women with generalized anxiety disorder (GAD).

Methods: In this cross-sectional study, 51 adult females with GAD answered the Barratt Impulsiveness Scale (BIS-11) and participated in a go/no-go task using food images. Anthropometric measurements were evaluated. A food frequency questionnaire and a snack test were used to study eating behavior. Pearson correlation and multiple linear regression were performed to analyze the variables of interest, adjusted by age.

Results: Impulsivity predicted intake of sugar $(p=0.016,95 \% \mathrm{Cl} 0.67-6.05)$, total fat $(p=0.007,95 \%$ $\mathrm{Cl} 0.62-3.71)$, and saturated fat $(\mathrm{p}=0.004,95 \% \mathrm{Cl} 0.30-1.48)$. The snack test showed a positive correlation between presence of impulsivity and intake of biscuits $(R=0.296 ; p=0.051)$. Response inhibition to food images in the go/no-go task paradigm did not predict BMI or food intake.

Conclusion: Impulsivity was predictive of higher sugar and saturated fat intake in women diagnosed with GAD. Our findings add to the literature regarding the association between neuropsychological factors and food consumption in this specific population.
\end{abstract}

Keywords: Eating behavior; generalized anxiety disorder; inhibitory control; impulsivity; overeating

\section{Introduction}

Generalized anxiety disorder (GAD) is characterized by persistent anxiety and excessive worrying about everyday life events for at least 6 months, associated with enduring subjective suffering, physical symptoms, and the feeling of loss of control over anxiety. ${ }^{1}$ It is a prevalent and disabling disorder ${ }^{1}$ and is considered a risk factor for both anorexia ${ }^{2}$ and obesity. ${ }^{3}$ Data on eating behavior patterns in anxious patients are very inconsistent, and the mechanisms by which some individuals have restrictive eating behaviors while others engage in overconsumption are still poorly understood. Personality traits, ${ }^{4}$ temperament, ${ }^{5}$ self-control, ${ }^{6,7}$ and changes in executive function and inhibitory control $^{8}$ seem to be associated with this observable dysfunctional eating behavior.

Impulsivity is a biological predisposition associated with rapid and unplanned reactions to internal and external

Correspondence: Natasha Kim de Oliveira da Fonseca, Universidade Federal do Rio Grande do Sul (UFRGS), Rua Ramiro Barcelos, 2350, CEP 90035-903, Porto Alegre, RS, Brazil.

E-mail: natasha.deoliveira@ hotmail.com

Submitted May 23 2019, accepted Nov 04 2019, Epub Feb 142020. stimuli, without considering their possible consequences. ${ }^{9}$ It is a behavioral pattern comprised by greater motor activation, less attention, and decreased planning strategies. ${ }^{9}$ Impulsivity can be seen in any individual. with or without psychiatric diagnoses, and can influence the severity and longitudinal course of different mental disorders. $^{10}$

Inhibitory control is characterized as the ability to regulate automatic behavioral responses. It is important for limiting engagement in rewarding behaviors, such as consuming highly palatable foods. ${ }^{11}$ Poor inhibitory control is associated with food intake, ${ }^{11,12}$ including higher intake in response to negative emotional states, ${ }^{13}$ obesity and weight gain, ${ }^{14,15}$ and failure of long-term weight-loss treatments. ${ }^{16}$ However, few studies have assessed these mechanisms in patients with anxiety disorders.

GAD occurs twice as often in women, ${ }^{17}$ who also have a higher risk of eating disorders. ${ }^{18}$ However, data

How to cite this article: Fonseca NKO, Molle RD, Costa MA, Gonçalves FG, Silva AC, Rodrigues Y, et al. Impulsivity influences food intake in women with generalized anxiety disorder. Braz $\mathrm{J}$ Psychiatry. 2020;42:382-388. http://dx.doi.org/10.1590/1516-44462019-0556 
regarding the association between GAD and dysfunctional eating behavior are inconsistent. Moreover, considering that both impulsivity and lack of inhibitory control may influence the relationship between presence of psychiatric disorders and eating behaviors, the main goal of the present study is to investigate the putative association between impulsivity, inhibitory control, and energy-dense food consumption in women with GAD. We hypothesized that impulsivity and poor inhibitory control to food stimuli would predict higher body mass index (BMI) and increased sugar and fat intake in this population.

\section{Methods}

\section{Participants}

Community-dwelling women diagnosed with GAD (according to DSM-5 criteria) were recruited to participate in this study through an advertisement placed in local media. Potential participants were screened by telephone with the Generalized Anxiety Disorder 7-item scale (GAD-7). ${ }^{19}$ Those who scored $\geqslant 10$ on this scale were invited to undergo an extensive evaluation with a trained psychiatrist or psychologist, which included a clinical psychiatric interview and the Mini-International Neuropsychiatric Interview (MINI). ${ }^{20}$ Patients were included in the study if they were aged $>18$ years and had a primary diagnosis of GAD. The exclusion criteria were presence of eating disorders, bipolar disorder, psychotic disorders, substance use disorders (except tobacco), or suicidal ideation in the preceding 6 months. Patients could be included in the study if they fulfilled the diagnostic criteria for major depression, as long as it was not the primary diagnosis and they scored no higher than 23 on the Hamilton Depression Rating Scale (HAM-D).

\section{Measures}

Anxiety and depression diagnoses and symptom severity The $\mathrm{MINI}^{20}$ is a structured and validated clinical diagnostic psychiatric interview, designed for administration by trained psychiatrists or psychologists, which yields psychiatric diagnoses according to the DSM-IV and ICD10 criteria. (For the purposes of this study, we made minor adaptations in order to address the DSM-5 diagnostic criteria.) This instrument has been validated for the Brazilian population. ${ }^{21}$

We used the Hamilton Anxiety Rating Scale (HAM-A), a widely used and well-validated rating scale, to evaluate anxiety severity, ${ }^{22}$ and the HAM-D ${ }^{23}$ to evaluate the severity of depression symptoms. As noted above, patients with severe depressive symptoms (HAM-D > 23) were excluded.

\section{Impulsivity}

The Barratt Impulsiveness Scale (BIS-11) is a 30 -item, self-administered rating scale that evaluates impulsivity as a multifaceted dimension. This scale has been translated and validated for use in Brazilian adults with good psychometric properties. ${ }^{24}$ Given the results of confirmatory factor analysis in our sample (Tables S1 and S2, available as online-only supplementary material), we did not use the BIS subdomains.

\section{Go/no-go task}

The "go/no-go" paradigm has high reliability for evaluation of inhibitory control. ${ }^{25}$ During the 20-minute task, neutral and food images were depicted on a computer screen and participants were instructed to press (or not) the space bar on the keyboard in response to each stimulus: they should press the space bar in response to "Go" stimuli (neutral images: office and bathroom objects) and not press the space bar when shown "No-Go" stimuli (foods and a third class of neutral images, namely sports objects). One hundred trials (in two blocks of 50) were presented for the neutral task and for the food task, for a total of 200 trials. Each trial was presented for $750 \mathrm{~ms}$, separated by a blank screen for $500 \mathrm{~ms}$ and preceded by a fixation point for $500 \mathrm{~ms}$. Images were presented using a ratio of $80 \%$ "go" to $20 \%$ "no-go" trials, aiming to induce a go response in a pseudo-randomized order, with three, four, or five go trials for every no-go trial. ${ }^{8}$ The food and neutral tasks were presented in a counterbalanced fashion. All tasks were programmed in Open Sesame software. ${ }^{26}$

\section{Food consumption}

We used the 135-item FFQ-Porto Alegre food frequency questionnaire to evaluate participants' usual food consumption in the preceding year. This instrument evaluates energy (calories), sugar (grams), total fat (grams), and saturated fat (grams) intake, and has been validated for use in Brazilian participants aged 12 to 90 years. ${ }^{27}$

\section{Snack test}

To evaluate food intake in the laboratory setting, we used the snack test. In this test, participants were invited to sample two types of biscuit and rate their palatability, crunchiness, and strength of flavor on separate visual analogue scales. They were allowed to consume as many biscuits as they wanted under the guise of sensory evaluation (bogus taste test). Participants were informed that any food left over would be discarded (adapted from Price et al. $\left.^{8}\right)$. The biscuits were Belvita Minis cocoa \& cereals $(1,932 \mathrm{~kJ}[460 \mathrm{kcal}] / 100 \mathrm{~g})$ and Belvita Minis milk \& oats $(1,900 \mathrm{~kJ}[452 \mathrm{kcal}] / 100 \mathrm{~g})$. The outcome was the number of biscuits consumed during 5 minutes in which the participant remained alone in the room, to minimize social desirability effects. The participants had eaten a standard meal before this task.

\section{Anthropometric evaluation}

The anthropometric parameters of interest were BMI and body composition. Weight was measured on a calibrated digital scale (capacity 200 kg, Toledo, São Bernardo do Campo, Brazil), and height, using a vertical stadiometer (resolution, $1 \mathrm{~mm}$ Holtain Limited, Crosswell, Wales, UK). Both measurements were obtained twice and the average 
value used for analyses. BMI, calculated as the weight in kilograms divided by the height in meters squared $\left(\mathrm{kg} / \mathrm{m}^{2}\right)$, was used to evaluate nutritional status. An InBody230 ${ }^{\circ}$ bioelectrical impedance analysis system (Perafita, Portugal) was used to evaluate body composition (expressed as fat mass percentage).

\section{Procedure}

Prospective participants who agreed to take part in the study signed an informed consent form and underwent a structured clinical interview to confirm GAD diagnosis. Those who met all inclusion criteria scheduled their second study visit, which was to take place in the morning, after a 12-hour fast. At this appointment, anthropometric evaluation was performed and a blood sample was collected by venipuncture. Participants were then offered a standardized snack, which consisted of a sevenunit serving of whole-grain toast (total energy $91 \mathrm{kcal}$, carbohydrates $19 \mathrm{~g}$, protein $2.5 \mathrm{~g}$, total fat $0.6 \mathrm{~g}$, dietary fiber $1.4 \mathrm{~g}$ ) and a cup of sugar-free tea, to break the fast and standardize any potential variations in hunger and satiety during administration of the scales (BIS-11 and FFQ-Porto Alegre) and neurocognitive task (go/no-go test). The snack test was done afterwards. The total evaluation time averaged 1 hour and 30 minutes to 2 hours, of which approximately 20 minutes were devoted to the neurocognitive task.

\section{Statistical analysis}

Data were described as mean \pm standard deviation (SD) for parametric quantitative variables, median and interquartile range for nonparametric quantitative variables, and as absolute and relative frequencies for qualitative variables. We performed correlation analyses between all variables using Pearson correlation; variables with $p<0.20$ on correlation analysis were included in the regression models. All models were adjusted for age. We used multiple linear regression for variables with normal distribution. All prerequisites for analysis were met, and data were analyzed in PASW Version 18.0. All tests were two-tailed, with a significance level of $p<0.05$.

Considering $80 \%$ statistical power and a significance level of $5 \%$, the sample size was calculated as 47 participants to detect a moderate association of at least 0.40 between food consumption and impulsivity.

\section{Ethics statement}

The study was approved by the ethics committee of Hospital de Clínicas de Porto Alegre (CAAE 61336416. 0.0000.5327).

\section{Results}

Our sample was comprised of 51 women diagnosed with GAD. All had moderate to severe anxiety symptoms, according to the Hamilton Anxiety Rating Scale. Of these participants, one did not complete the BIS rating scale and six were unable to perform the go/no-go task due to computer issues.

Among the 44 participants who completed all measures and tasks, the mean (SD) age was 33 (11.32) years. All were categorized into socioeconomic class B or C according to the Brazilian Market Research Association criteria, which corresponds to middle class. ${ }^{28}$ The mean BMI was $27.46(6.55) \mathrm{kg} / \mathrm{m}^{2}$, classified as overweight and the majority of participants $(79.5 \%)$ had high body fat percentage (mean [SD] 37.1\% [8.7]). The mean (SD) BIS-11 score was 71.6 (9.9). The mean (SD) number of commission errors in the go/no-go task for food images was 2.98 (2.96), while the mode for this task was $2(0-12)$.

Impulsivity measured by the BIS-11 correlated positively with energy, sugar, total fat, and saturated fat intake, and, as expected, with worse inhibitory control $(R=0.442 ; p=0.003)$ (Table 1). We also found a positive correlation between impulsivity and intake of biscuits in the snack test $(R=0.296 ; p=0.051)$ (Table 1).

We used multiple linear regression (Table 2) to ascertain whether impulsivity and poor inhibitory control to food stimuli were able to predict higher BMI, snack intake, and sugar and fat consumption in women with GAD, adjusted by age. Because energy intake correlated strongly with sugar and fat intake, we evaluated diet quality by selecting hyperpalatable nutrients (sugar and fat) as outcomes in the regression models. Likewise, since BMI and \%fat are collinear and most studies of non-anxious populations reported data on $\mathrm{BMI}$ and not on \%fat, we included only $\mathrm{BMI}$ data in the regression models.

The significant regression models for sugar $(b=3.36$; $t=2.53, \mathrm{p}=0.016,95 \% \mathrm{Cl} 0.67-6.05)$, total fat $(\mathrm{b}=2.16$; $t=2.82, \mathrm{p}=0.007,95 \% \mathrm{Cl} 0.62-3.71)$, and saturated fat intake $(\mathrm{b}=0.89 ; t=3.05, \mathrm{p}=0.004,95 \% \mathrm{Cl} 0.30-1.48)$ showed that only impulsivity predicted higher food consumption in women with GAD (Table 2). For each additional point on the BIS-11, the model predicted an additional intake of $2.2 \mathrm{~g}$ total fat, $0.9 \mathrm{~g}$ saturated fat, and $3.4 \mathrm{~g}$ of sugar. This suggested a specific pattern of eating behavior in our sample. Regression models for monounsaturated and polyunsaturated fat were also tested, but the results were not significant (data available in Table S3, available as online-only supplementary material).

The poor response inhibition to food images in the go/ no-go task paradigm was not associated with BMI or food intake (Table 2). Furthermore, the correlation between impulsivity and snack test intake did not remain significant on regression analysis (Table 2).

\section{Discussion}

This study investigated the association between impulsivity, inhibitory control, and food intake in women diagnosed with GAD. We found that: 1) impulsivity predicted higher sugar, total fat and saturated fat intake; 2) BMI was not influenced by impulsivity; 3) inhibitorycontrol in response to food was not related to food intake or BMI; however, 4) inhibitory-control in response to food was correlated with impulsivity (BIS).

Our data suggest that intake of sugar and saturated fat during the past year was higher among anxious women 
Table 1 Correlations between impulsivity, inhibitory control measures, BMI, and food intake measures

\begin{tabular}{|c|c|c|c|c|c|c|c|c|c|}
\hline & Age & Energy & Sugar & Fat & Saturated fat & BMI & Fat $\%$ & $\mathrm{BIS}$ & No-go food \\
\hline \multicolumn{10}{|l|}{ Age } \\
\hline $\begin{array}{l}\text { Pearson correlation } \\
\text { p-value }\end{array}$ & 1 & & & & & & & & \\
\hline \multicolumn{10}{|l|}{ Energy } \\
\hline $\begin{array}{l}\text { Pearson correlation } \\
\text { p-value }\end{array}$ & $\begin{array}{l}-0.168 \\
0.275\end{array}$ & 1 & & & & & & & \\
\hline \multicolumn{10}{|l|}{ Sugar } \\
\hline Pearson correlation & -0.190 & $0.882 *$ & 1 & & & & & & \\
\hline$p$-value & 0.217 & 0.000 & & & & & & & \\
\hline \multicolumn{10}{|l|}{ Fat } \\
\hline Pearson correlation & -0.159 & $0.945^{*}$ & $0.758^{*}$ & 1 & & & & & \\
\hline$p$-value & 0.304 & 0.000 & 0.000 & & & & & & \\
\hline \multicolumn{10}{|l|}{ Saturated fat } \\
\hline Pearson correlation & -0.010 & $0.883^{*}$ & $0.716^{*}$ & $0.930 *$ & 1 & & & & \\
\hline$p$-value & 0.946 & 0.000 & 0.000 & 0.000 & & & & & \\
\hline \multicolumn{10}{|l|}{ BMI } \\
\hline Pearson correlation & $0.360^{\dagger}$ & 0.029 & 0.150 & -0.065 & -0.054 & 1 & & & \\
\hline $\mathrm{p}$-value & 0.016 & 0.853 & 0.332 & 0.676 & 0.728 & & & & \\
\hline \multicolumn{10}{|l|}{ Fat $\%$} \\
\hline Pearson correlation & $0.430 *$ & -0.028 & 0.079 & -0.120 & -0.107 & $0.849 *$ & 1 & & \\
\hline$p$-value & 0.004 & 0.856 & 0.612 & 0.438 & 0.491 & 0.000 & & & \\
\hline \multicolumn{10}{|l|}{ BIS } \\
\hline Pearson correlation & -0.084 & $0.389 *$ & $0.399 *$ & $0.341^{\dagger}$ & $0.389 *$ & 0.174 & 0.074 & 1 & \\
\hline$p$-value & 0.586 & 0.009 & 0.007 & 0.023 & 0.009 & 0.258 & 0.633 & & \\
\hline \multicolumn{10}{|l|}{ No-go food } \\
\hline Pearson correlation & -0.121 & 0.037 & 0.158 & -0.055 & -0.001 & 0.287 & 0.204 & $0.442 *$ & 1 \\
\hline$p$-value & 0.435 & 0.810 & 0.304 & 0.724 & 0.995 & 0.059 & 0.184 & 0.003 & \\
\hline \multicolumn{10}{|l|}{ Snack test } \\
\hline Pearson correlation & 0.044 & 0.017 & -0.102 & 0.106 & 0.221 & -0.097 & -0.142 & 0.296 & 0.151 \\
\hline $\mathrm{p}$-value & 0.777 & 0.910 & 0.511 & 0.494 & 0.149 & 0.533 & 0.359 & $0.051^{\dagger}$ & 0.329 \\
\hline
\end{tabular}

$\mathrm{BIS}=$ Barratt Impulsiveness Scale; BMI = body mass index.

* Correlation significant at $p<0.01$ (two-tailed).

${ }^{\dagger}$ Correlation significant at $p<0.05$ (two-tailed).

who were more impulsive, which is in agreement with previous studies associating food intake and impulsivity in individuals without anxiety disorders. ${ }^{25}$

The association of sugar intake and impulsivity found in our study is in agreement with the literature on normalweight healthy women. ${ }^{29}$ According to Guerrieri et al., both sugar intake and thoughts and behaviors linked to eating disorders were significantly greater in individuals with high impulsivity. ${ }^{29}$

Impulsivity is characterized by poor self-control ${ }^{25}$ and by increased sensitivity to reward, ${ }^{9}$ which are both related to overeating. ${ }^{30,31}$ These behaviors are associated to dysregulation in neurotransmitters such as serotonin (5-HT) and dopamine. 5-HT pathways seem to play a role in impulsivity ${ }^{32}$ and in "waiting to obtain reward" with the purpose of achieving a delayed reward. Moreover, the mesocorticolimbic dopamine system receives and integrates information related to both hedonic and homeostatic food stimuli. ${ }^{33}$ The association between overconsumption of hyperpalatable or rewarding foods and impulsivity demonstrated in our study may reflect imbalances in dopaminergic or/and serotoninergic signaling, which have also been described in anxiety disorders. ${ }^{34}$ These neurotransmitters also promote two-way communications between areas of the prefrontal cortex and amygdala.

The literature has reported that patients with deficits in executive functions, such as inhibition control, often score higher on the BIS-11, ${ }^{35}$ which is in agreement with our finding. Moreover, according to Van Der Laan et al., ${ }^{36}$ higher levels of impulsivity (measured both by a subscale from the BIS and by the delay discounting task) were associated with greater brain striatal activation for highenergy food stimuli in 20 women with weight concerns. ${ }^{36}$ Individuals with high sensitivity to reward and frequent disinhibited behavior may be more vulnerable to overeating hyperpalatable foods when exposed to the socalled obesogenic or food-abundant environment, leading to long-term weight gain. ${ }^{25}$

In our study, only intake of saturated fat within total fat (monounsaturated and polyunsaturated fat were tested) was associated with impulsivity. Saturated fat is associated with cardiovascular disease and mortality, ${ }^{37}$ and generally related to an unhealthy lifestyle, since 
Table 2 Multiple linear regression models performed to analyze the influence of impulsivity (BIS-11) and inhibitory control on nutrient intake and BMI

\begin{tabular}{|c|c|c|c|c|}
\hline & B & SE & $t$ & $\mathrm{p}$-value \\
\hline $\begin{array}{l}\text { Sugar }\left(R=0.430 \text {, adjusted } R^{2}=0.124\right) \\
\text { Constant } \\
\text { Age } \\
\text { Impulsivity (BIS) } \\
\text { Inhibitory control (no-go food) }\end{array}$ & $\begin{array}{c}-76.957 \\
-1.173 \\
3.362 \\
-1.078\end{array}$ & $\begin{array}{c}99.064 \\
1.051 \\
1.331 \\
4.465\end{array}$ & $\begin{array}{l}-0.777 \\
-1.116 \\
2.526 \\
-0.241\end{array}$ & $\begin{array}{c}<0.05^{*} \\
0.442 \\
0.271 \\
0.016^{\dagger} \\
0.810\end{array}$ \\
\hline $\begin{array}{l}\text { Fat }\left(R=0.438, \text { adjusted } R^{2}=0.131\right) \\
\text { Constant } \\
\text { Age } \\
\text { Impulsivity (BIS) } \\
\text { Inhibitory control (no-go food) }\end{array}$ & $\begin{array}{c}-18.477 \\
-0.647 \\
2.163 \\
-4.377\end{array}$ & $\begin{array}{c}56.993 \\
0.604 \\
0.766 \\
2.569\end{array}$ & $\begin{array}{l}-0.324 \\
-1.071 \\
2.825 \\
-1.704\end{array}$ & $\begin{array}{c}<0.05^{*} \\
0.747 \\
0.291 \\
0.007^{\dagger} \\
0.096\end{array}$ \\
\hline $\begin{array}{l}\text { Saturated Fat }\left(R=0.434 \text {, adjusted } R^{2}=0.128\right) \\
\text { Constant } \\
\text { Age } \\
\text { Impulsivity (BIS) } \\
\text { Inhibitory control (no-go food) }\end{array}$ & $\begin{array}{c}-26.404 \\
0.007 \\
0.893 \\
-1.321\end{array}$ & $\begin{array}{c}21.804 \\
0.231 \\
0.293 \\
0.983\end{array}$ & $\begin{array}{c}-1.211 \\
0.032 \\
3.049 \\
-1.344\end{array}$ & $\begin{array}{c}<0.05^{*} \\
0.233 \\
0.975 \\
0.004^{\dagger} \\
0.186\end{array}$ \\
\hline $\begin{array}{l}\text { BMI }\left(R=0.495, \text { adjusted } R^{2}=0.188\right) \\
\text { Constant } \\
\text { Age } \\
\text { Impulsivity (BIS) } \\
\text { Inhibitory control (no-go food) }\end{array}$ & $\begin{array}{c}14.234 \\
0.233 \\
0.049 \\
0.670\end{array}$ & $\begin{array}{l}7.556 \\
0.080 \\
0.101 \\
0.341\end{array}$ & $\begin{array}{l}1.884 \\
2.908 \\
0.487 \\
1.967\end{array}$ & $\begin{array}{c}<0.05^{*} \\
0.067 \\
0.006^{\dagger} \\
0.629 \\
0.056\end{array}$ \\
\hline
\end{tabular}

BIS = Barratt Impulsiveness Scale; BMI = body mass index; SE = standard error .

* Regression model significant at $p<0.05$.

${ }^{\dagger}$ Independent variables significant at $p<0.05$.

ultra-processed foods are significant sources of saturated fat, sodium, and added sugar intake. ${ }^{38}$ Our results are consistent with the behavioral pattern observed by Sarmugam \& Worsley, in which impulsive consumers eat more fast foods, takeaways, convenience meals, salted snacks, ready-made sauces, and mixes as compared to healthy eaters. ${ }^{39}$ Thus, these individuals may be at higher risk for cardiovascular disease. Knowing that anxiety is also considered an independent risk factor for cardiovascular diseases, ${ }^{40}$ eating behavior should be a focus of attention for health professionals dealing with anxious individuals.

Although many studies have suggested a relationship between response inhibition and food intake or response inhibition and obesity, ${ }^{25,41}$ our study did not find a significant correlation between poorer inhibitory control in response to food images and food consumption or BMI, probably due to our small sample size. It is possible that the mechanisms by which impulsivity acts on eating behavior in anxious patients can be different from those described in individuals without GAD. Furthermore, some of the constructs that comprise impulsivity as it relates to anxiety disorders (attention and planning) could not be captured by the task we used.

Impulsivity and snack intake correlated positively in this study; however, this relationship did not remain statistically significant on regression analysis. In contrast to our results, Price et al. ${ }^{8}$ demonstrated that response inhibition deficits on a food go/no-go task predicted greater snack intake in overweight/obese individuals who scored low on restrained eating measurement. This study suggested that overeating was mediated by poorer response inhibition to food. Moreover, deficits in the go/no-go task were also associated with BMI in a study of female adolescents without anxiety disorder. ${ }^{42}$
In our sample, only age was associated with higher $\mathrm{BMI}$, as already described for the general population. ${ }^{43}$ Moreover, in the current study, BMI was not associated with impulsivity, which contradicts data from a recent meta-analysis. ${ }^{44}$ However, this meta-analysis also suggested that the instrument used to evaluate impulsivity and the domain of impulsivity assessed can result in different effect sizes on BMI. ${ }^{44}$ Furthermore, other factors - such as physical activity, trait food craving, perceived self-regulatory success, specific impulsivity domains, and/or eating styles - can interfere with the total effect of impulsivity on BMI. ${ }^{45}$

The main limitations of the present study were the small sample size and the cross-sectional design, which precluded any determination of a causal relationship between the variables. However, as previously determined by our sample size calculation and confirmed by the significance of our results, the study was powered to detect associations among the outcomes of interest. An additional limitation is that we did not test for attentiondeficit/hyperactivity disorder (ADHD) or its sub-syndromal symptoms, nor for autism spectrum disorders, conditions which may alter executive function and worsen performance on neurocognitive tasks. However, no participants had evidence of these diagnoses on clinical evaluation. Longitudinal studies including individuals without GAD are needed to help understand eating behavior patterns in this population.

Our finding of impulsivity as a predictor of higher sugar and saturated fat intake in women diagnosed with GAD might elucidate the association between impulsivity and food consumption in a population subtype at increased risk of eating disorders and cardiovascular disease. Our results suggest that impulsivity is one of the factors that 
lead to overconsumption and, consequently, to overweight in the long term. This knowledge may contribute to the development of preventive strategies against weight gain and management strategies for overweight in order to reduce morbidity in patients with anxiety disorders.

\section{Acknowledgements}

Study funded by Conselho Nacional de Desenvolvimento Científico e Tecnológico (CNPq; PPS, 478820/2010), Fundo de Incentivo à Pesquisa - Hospital de Clínicas de Porto Alegre (FIPE-HCPA; 16-0552), Coordenação de Aperfeiçoamento de Pessoal de Nível Superior (CAPES). The financial backers played no role in the design and analysis of the study or in the writing of this article. The authors thank the participants for their time and support.

\section{Disclosure}

The authors report no conflicts of interest.

\section{References}

1 Wittchen HU. Generalized anxiety disorder: prevalence, burden, and cost to society. Depress Anxiety. 2002;16:162-71.

2 Dellava JE, Thornton LM, Hamer RM, Strober M, Plotnicov K, Klump $\mathrm{KL}$, et al. Childhood anxiety associated with low BMI in women with anorexia nervosa. Behav Res Ther. 2010;48:60-7.

3 Gariepy G, Nitka D, Schmitz N. The association between obesity and anxiety disorders in the population: a systematic review and meta-analysis. Int J Obes (Lond). 2010;34:407-19.

4 Gerlach G, Loeber S, Herpertz S. Personality disorders and obesity: a systematic review. Obes Rev. 2016;17:691-723.

5 Zhou Z, SooHoo M, Zhou Q, Perez M, Liew J. Temperament as risk and protective factors in obesogenic eating: relations among parent temperament, child temperament, and child food preference and eating. J Genet Psychol. 2019;180:75-9.

6 Nederkoorn C, Houben K, Hofmann W, Roefs A, Jansen A. Control yourself or just eat what you like? Weight gain over a year is predicted by an interactive effect of response inhibition and implicit preference for snack foods. Health Psychol. 2010;29:389-93.

7 Balani R, Herrington H, Bryant E, Lucas C, Kim SC. Nutrition knowledge, attitudes, and self -regulation as predictors of overweight and obesity. J Am Assoc Nurse Pract. 2019;31:502-10.

8 Price M, Lee M, Higgs S. Food-specific response inhibition, dietary restraint and snack intake in lean and overweight/obese adults: a moderated-mediation model. Int J Obes (Lond). 2016;40:877-82.

9 Moeller FG, Barratt ES, Dougherty DM, Schmitz JM, Swann AC. Psychiatric aspects of impulsivity. Am J Psychiatry. 2001;158: 1783-93.

10 Cale EM. A quantitative review of the relations between the "Big 3" higher order personality dimensions and antisocial behavior. J Res Pers. 2006;40:250-84.

11 Houben K. Overcoming the urge to splurge: influencing eating behavior by manipulating inhibitory control. J Behav Ther Exp Psychiatry. 2011;42:384-8.

12 Annesi JJ. Effects of a naturally occurring stressor on health behaviors and their psychosocial correlates. Psychol Health Med. 2019 Aug 271-12. doi: 10.1080/13548506.2019.1658882. [Epub ahead of print]

13 Bekker $\mathrm{MH}$, van de Meerendonk $\mathrm{C}$, Mollerus J. Effects of negative mood induction and impulsivity on self-perceived emotional eating. Int J Eat Disord. 2004;36:461-9.

14 Guerrieri R, Nederkoorn C, Jansen A. The interaction between impulsivity and a varied food environment: its influence on food intake and overweight. Int J Obes (Lond). 2008;32:708-14.

15 Chen S, Jia Y, Woltering S. Neural differences of inhibitory control between adolescents with obesity and their peers. Int $\mathrm{J}$ Obes (Lond). 2018;42:1753-61.
16 Thamotharan S, Lange K, Zale EL, Huffhines L, Fields S. The role of impulsivity in pediatric obesity and weight status: a meta-analytic review. Clin Psychol Rev. 2013;33:253-62.

17 Steel Z, Marnane C, Iranpour C, Chey T, Jackson JW, Patel V, et al. The global prevalence of common mental disorders: a systematic review and meta-analysis 1980-2013. Int J Epidemiol. 2014;43: 476-93.

18 Striegel-Moore RH, Rosselli F, Perrin N, DeBar L, Wilson GT, May A, et al. Gender difference in the prevalence of eating disorder symptoms. Int J Eat Disord. 2009;42:471-4.

19 Spitzer RL, Kroenke K, Williams JB, Löwe B. A brief measure for assessing generalized anxiety disorder: the GAD-7. Arch Intern Med. 2006;166:1092-7.

20 Sheehan DV, Lecrubier Y, Sheehan KH, Amorim P, Janavs J, Weiller E, et al. The Mini-International Neuropsychiatric Interview (M.I.N.I.): the development and validation of a structured diagnostic psychiatric interview for DSM-IV and ICD-10. J Clin Psychiatry. 1998;59 Suppl 20: 22-33; quiz 34-57.

21 Amorim P. Mini International Neuropsychiatric Interview (MINI): validação de entrevista breve para diagnóstico de transtornos mentais. Braz J Psychiatry. 2000;22:106-15.

22 Shear MK, Vander Bilt J, Rucci P, Endicott J, Lydiard B, Otto MW, et al. Reliability and validity of a structured interview guide for the Hamilton Anxiety Rating Scale (SIGH-A). Depress Anxiety. 2001;13:166-78.

23 Hamilton M. Development of a rating scale for primary depressive illness. Br J Soc Clin Psychol. 1967;6:278-96.

24 Malloy-Diniz LF, Mattos P, Leite WB, Abreu N, Coutinho G, de Paula $\mathrm{JJ}$, et al. Tradução e adaptação cultural da Barratt Impulsiveness Scale (BIS-11) para aplicação em adultos brasileiros. Braz J Psychiatry. 2010;59:99-105.

25 Vainik U, Dagher A, Dubé L, Fellows LK. Neurobehavioural correlates of body mass index and eating behaviours in adults: a systematic review. Neurosci Biobehav Rev. 2013;37:279-99.

26 Mathôt S, Schreij D, Theeuwes J. OpenSesame: an open-source, graphical experiment builder for the social sciences. Behav Res Methods. 2012;44:314-24.

27 Henn RL, Fuchs SC, Moreira LB, Fuchs FD. Development and validation of a food frequency questionnaire (FFQ-Porto Alegre) for adolescent, adult and elderly populations from Southern Brazil. Cad Saude Publica. 2010;26:2068-79.

28 Associação Brasileira de Empresas de Pesquisa (ABEP). Critério de Classificação Econômica Brasil 2008 [Internet]. 2012 Jun [cited 2019 Nov 26]. cmicro.fgv.br/sites/cmicro.fgv.br/files/file/CCEB\%20FGV\%20\% 2825-6-2012\%29.pdf

29 Guerrieri R, Nederkoorn C, Stankiewicz K, Alberts H, Geschwind N, Martijn $\mathrm{C}$, et al. The influence of trait and induced state impulsivity on food intake in normal-weight healthy women. Appetite. 2007;49: 66-73.

30 Franken $\mathrm{IH}$, Muris $\mathrm{P}$. Individual differences in reward sensitivity are related to food craving and relative body weight in healthy women. Appetite. 2005;45:198-201.

31 Annesi JJ. Moderation of mood in the transfer of self-regulation from an exercise to an eating context: short- and long-term effects on dietary change and obesity in women. Int J Behav Med. 2019;26: 323-8.

32 Dalley JW, Roiser JP. Dopamine, serotonin and impulsivity. Neuroscience. 2012;215:42-58.

33 Silveira PP, Pokhvisneva I, Gaudreau H, Atkinson L, Fleming AS, Sokolowski MB, et al. Fetal growth interacts with multilocus genetic score reflecting dopamine signaling capacity to predict spontaneous sugar intake in children. Appetite. 2018;120:596-601.

34 Martin El, Ressler KJ, Binder E, Nemeroff CB. The neurobiology of anxiety disorders: brain imaging, genetics, and psychoneuroendocrinology. Clin Lab Med. 2010;30:865-91.

35 Stanford MS, Mathias C, Dougherty DM, Lake SL, Anderson NE, Patton JH. Fifty years of the Barratt Impulsiveness Scale: an update and review. Pers Individ Dif. 2009;47:385-95.

36 van der Laan LN, Barendse ME, Viergever MA, Smeets PA. Subtypes of trait impulsivity differentially correlate with neural responses to food choices. Behav Brain Res. 2016;296:442-50.

37 O'Sullivan TA, Hafekost K, Mitrou F, Lawrence D. Food sources of saturated fat and the association with mortality: a meta-analysis. Am J Public Health. 2013;103:e31-42. 
38 Tseng M, Neill DB, Teaford SF, Nazmi A. Alternative myplate menus: effects of ultra-processed foods on saturated fat, sugar, and sodium content. J Nutr Educ Behav. 2018;50:258-66.e1.

39 Sarmugam R, Worsley A. Dietary behaviours, impulsivity and food involvement: identification of three consumer segments. Nutrients. 2015;7:8036-57.

40 Ouakinin SR. Anxiety as a risk factor for cardiovascular diseases. Front Psychiatry. 2016;7:25.

41 Kohl SH, Veit R, Spetter MS, Günther A, Rina A, Lührs M, et al. Real-time fMRI neurofeedback training to improve eating behavior by self-regulation of the dorsolateral prefrontal cortex: a randomized controlled trial in overweight and obese subjects. Neuroimage. 2019;191:596-609.
42 Batterink L, Yokum S, Stice E. Body mass correlates inversely with inhibitory control in response to food among adolescent girls: an fMRI study. Neuroimage. 2010;52:1696-703.

43 Alexander CM, Landsman PB, Grundy SM. The influence of age and body mass index on the metabolic syndrome and its components. Diabetes Obes Metab. 2008;10:246-50.

44 Emery RL, Levine MD. Questionnaire and behavioral task measures of impulsivity are differentially associated with body mass index: a comprehensive meta-analysis. Psychol Bull. 2017;143: 868-902.

45 Meule A, Blechert J. Indirect effects of trait impulsivity on body mass. Eat Behav. 2017;26:66-9 